\title{
Targeting complement cascade: an alternative strategy for COVID-19
}

\author{
Sureshbabu Ram Kumar Pandian ${ }^{1}$ (D) . Sankarganesh Arunachalam ${ }^{1} \cdot$ Venkataraman Deepak $^{1,2}$. \\ Selvaraj Kunjiappan ${ }^{1} \cdot$ Krishnan Sundar $^{1}$
}

Received: 21 May 2020 / Accepted: 3 October 2020 / Published online: 19 October 2020

(c) King Abdulaziz City for Science and Technology 2020

\begin{abstract}
The complement system is a stakeholder of the innate and adaptive immune system and has evolved as a crucial player of defense with multifaceted biological effects. Activation of three complement pathways leads to consecutive enzyme reactions resulting in complement components (C3 and C5), activation of mast cells and neutrophils by anaphylatoxins (C3a and C5a), the formation of membrane attack complex (MAC) and end up with opsonization. However, the dysregulation of complement cascade leads to unsolicited cytokine storm, inflammation, deterioration of alveolar lining cells, culminating in acquired respiratory destructive syndrome (ARDS). Similar pathogenesis is observed with the middle east respiratory syndrome (MERS), severe acquired respiratory syndrome (SARS), and SARS-CoV-2. Activation of the lectin pathway via mannose-binding lectin associated serine protease 2 (MASP2) is witnessed under discrete viral infections including COVID19. Consequently, the spontaneous activation and deposits of complement components were traced in animal models and autopsy of COVID-19 patients. Pre-clinical and clinical studies evidence that the inhibition of complement components results in reduced complement deposits on target and non-target tissues, and aid in recovery from the pathological conditions of ARDS. Complement inhibitors (monoclonal antibody, protein, peptide, small molecules, etc.) exhibit great promise in blocking the activity of complement components and its downstream effects under various pathological conditions including SARS-CoV. Therefore, we hypothesize that targeting the potential complement inhibitors and complement cascade to counteract lung inflammation would be a better strategy to treat COVID-19.
\end{abstract}

Keywords SARS-CoV-2 $\cdot$ ARDS $\cdot$ Inflammation $\cdot$ MASP2 $\cdot$ Complement cascade $\cdot$ Complement inhibitors

\section{Introduction}

Innate immunity plays a critical role against various invading pathogens, in that, antigen-presenting cells, physical barriers, complement components, coagulation cascade, and immunoglobulins synergistically regulate opsonization, inflammation, and phagocytosis (Maloney et al. 2020). Innate immunity is massive and erstwhile it is puzzling to decide where the system ends, and the rest of the coordination begins (Beutler 2004). A gridded network is maintained by these immune components to preserve homeostasis and

Sureshbabu Ram Kumar Pandian

srkpandian@gmail.com

1 Department of Biotechnology, School of Bio and Chemical Engineering, Kalasalingam Academy of Research and Education, Krishnankoil, Tamilnadu 626126, India

2 Department of Human Sciences, University of Derby, London, United Kingdom to evade unsought immune response (Maloney et al. 2020). Although the innate immune system may not identify every antigen entering the host, it can recognize diverse microorganisms mainly based on pathogen-associated molecular patterns (PAMPs) present on the cell surface. The notable examples of PAMPs are bacterial lipopolysaccharides, peptidoglycan, lipoteichoic acids, mannans, bacterial DNA, double-stranded RNA, glucans (Medzhitov and Janeway Jr 2000), and viral surface protein (Wang and Liu 2016).

Duly, the complement system is a wing of an innate immune response having multifaceted biological effects against a wide range of bacterial, fungal, and viral infections. The complement cascade consists of soluble factors and cell surface receptors that can sensitize and counteract against both invading- (Stoermer and Morrison 2011) and selfantigens (Conigliaro et al. 2019). The complement system bridges the innate and adaptive immune response through humoral immunity, and by modulating T- and B-cell functions (Carroll 2004). The potential complement components 
and their role in innate immunity are listed in Table 1 . Neutrophils and mast cells are activated by the complement cascade and eventually act as key mediators of inflammation in several diseases and disorders (Mollnes et al. 2002). Complement pathways, which, when activated, lead to consecutive enzyme reactions, breakdown of complement components $\mathrm{C} 3$ and $\mathrm{C} 5$, and, result in by-products formation (C3a and $\mathrm{C} 5 \mathrm{a})$. These anaphylatoxins elicit a plethora of physiochemical responses that in turn activate phagocytic cells, release cytokines, chemokines, reactive oxygen species (ROS), adhesion molecules, and inflammation at the site of infection (Sarma et al. 2006). Immunoglobulins and cytokines are critical components of antiviral immunity (Smith and Nemerow 2019). Antibodies neutralize viruses by preventing cell membrane binding, inhibiting membrane fusion, and penetration with the disassembly of viral capsid proteins. Besides, antibody-dependent cellular cytotoxicity and antibody-dependent cellular phagocytosis culminate in reducing viral infections through classical complement cascade (Smith and Nemerow 2019) that results in opsonization and phagocytosis. However, inappropriate activation of the complement system exacerbates many acute lung injury disorders (Sarma et al. 2006). Moreover, many pathogens have acquired resistance to complement, which leads to exploiting the complement molecules and facilitates inflammation (Agrawal et al. 2017).

In this sense, the regulation and dysregulation of complement systems and their sought-after roles in various pathological conditions have been studied (Carroll 2004; Guo and Ward 2005; Rus et al. 2005; Conigliaro et al. 2019). In fact, there are three main phases of complement activation such as (1) recognition of foreign molecules, (2) formation of convertase enzymes that can cleave $\mathrm{C} 3$ and C5, and (3) fabrication of MAC for cell lysis (Rus et al. 2005). The classical, alternative, and mannose-binding lectin (MBL) pathways are activation cascades of various host-pathogen interaction conditions, converging at the juncture $\mathrm{C} 3$, from where the central complement cascade proceeds (Stoermer and Morrison 2011). Among the three pathways of complement activation, the MBL pathway is primary in viral infections (Matsushita and Fujita 1992; Kjaer et al. 2013) to induce a proinflammatory response

Table 1 Represents the complement components and their role in innate immunity

\begin{tabular}{|c|c|c|c|}
\hline S. no. & $\begin{array}{l}\text { Complement } \\
\text { components }\end{array}$ & Role in innate immune system & References \\
\hline 1. & $\mathrm{C} 1$ & $\begin{array}{l}\text { Circulate in plasma in huge amount; link adaptive and humoral immunity } \\
\text { to complement system }\end{array}$ & Mak et al. (2014) \\
\hline 2. & $\mathrm{C} 2$ & $\begin{array}{l}\text { It is necessary for the formation of } \mathrm{C} 3 \text { convertase; a key enzyme for com- } \\
\text { plement activation }\end{array}$ & Krishnan et al. (2009) \\
\hline 3. & $\mathrm{C} 3$ & $\begin{array}{l}\text { Act as point of convergence of activation pathways; enhance direct effector } \\
\text { functions; coordinate downstream immune response }\end{array}$ & Ricklin et al. (2016) \\
\hline 4. & $\mathrm{C} 3 \mathrm{a}$ & $\begin{array}{l}\text { Act as anaphylatoxin; trigger granulation of mast cells and basophils; can } \\
\text { cause smooth muscle contraction, increase in capillary permeability, } \\
\text { vasodilation }\end{array}$ & Mak and Saunders (2006) and Yang (2013) \\
\hline 5. & $\mathrm{C} 3 \mathrm{~b}$ & $\begin{array}{l}\text { Initiating MAC assembly; enabling the pathogens to bind on phagocytes } \\
\text { expressing CR1; solubilizing immune complexes; enhance antigen pres- } \\
\text { entation to T cells; directly provide defense against virus }\end{array}$ & Mak et al. (2014) \\
\hline 6 & $\mathrm{C} 5$ & Helps to form membrane attack complex & \\
\hline 7 & $\mathrm{C} 5 \mathrm{a}$ & $\begin{array}{l}\text { Stimulate neutrophil degranulation and the respiratory burst; macrophage } \\
\text { and monocytes enhance their expression of adhesion molecules in } \\
\text { response to C5a; can cause smooth muscle contraction, increase in capil- } \\
\text { lary permeability, vasodilation }\end{array}$ & Mak and Saunders (2006) and Yang (2013) \\
\hline 8. & $\mathrm{C} 5 \mathrm{~b}$ & $\begin{array}{l}\text { First complement component to initiate MAC formation and responsible } \\
\text { for cytolytic function of complement }\end{array}$ & Chow (2005) \\
\hline 9. & C6, 7, 8, 9 & Forming membrane attack complex & Ábel and Agnello (2004) \\
\hline 10. & Factor B & $\begin{array}{l}\text { Component of the alternative pathway and form a zymogen complex; } \\
\text { cleaved by factor } \mathrm{D} \text {; functionally similar to component } \mathrm{C} 2\end{array}$ & Pangburn (1986) and Schwaeble et al. (2020) \\
\hline 11. & Factor D & $\begin{array}{l}\text { Highly specific serine protease cleaves factor B; necessary for the forma- } \\
\text { tion of C } 3 \text { convertase }\end{array}$ & Forneris and Gros (2013) \\
\hline 12. & Factor $\mathrm{H}$ & $\begin{array}{l}\text { Essential for regulating alternative pathway; regulates the formation of } \mathrm{C} 3 \\
\text { and C5 convertases; controls complement-mediated damage }\end{array}$ & Ferreira et al. (2010) and Cree (2014) \\
\hline 13. & Factor I & Cleaves $\mathrm{C} 4 \mathrm{~b}$ and $\mathrm{C} 3 \mathrm{~b}$ & Du Clos and Mold (2013) \\
\hline 14. & MASP-1 & Supporting the activation of MBL pathway with MASP-2 & Dobó et al. (2009) \\
\hline 15. & MASP-2 & Directly activate MBL pathway & Dobó et al. (2009) \\
\hline
\end{tabular}


(Ling et al. 2012). For instance, human pathogenic viruses including HIV, SARS-CoV, Ebola virus, Dengue virus (DENV), and West Nile virus (WNV) have been found to directly interact with MBL (Stoermer and Morrison 2011). The dysregulation of the complement system plays key roles in the pathogenesis of respiratory disorders like acute lung injury (ALI). The highly pathogenic viruses such as influenza A, H1N1, H5N1, H7N9, SARS-CoV, and MERS-CoV cause ALI. Therefore, treatment with C3aR antagonist or anti-C5a antibody was applied to reduce the severity of lung inflammation in H5N1-infected mice (Sun et al. 2013; Wang et al. 2015; Huang et al. 2020).

MBL gene polymorphism is also a susceptible factor for viral invasion (Zhang et al. 2005). Functional polymorphisms of G-2518A at the chemokine (CeC motif) ligand 2 gene (CCL2) and MBL codon of 54 variants (A/B) are susceptible against SARS, and believed to enhance the risk of SARS-CoV infection (Tu et al. 2015). The activation of MBL pathway by altering the MASP-2 binding motif leads to the generation of $\mathrm{C} 3$ convertase, MAC formation, and lung injury (Shen et al. 2020). MASP-2 either cleaves the complement component $\mathrm{C} 4$ and $\mathrm{C} 2$ to generate C3 convertase (Farrar et al. 2006) or directly cleave C3 (Schwaeble et al. 2011). The interaction between MBL and SARS-S is based on a single N-linked glycosylation site in SARS-S (N330) (Zhou et al. 2010).

Upregulation of complement genes MASP1 and ficolin-1 were observed with the primary infection of SARSCoV-1 with the ferret model (Cameron et al. 2012), which is in agreement with a recent preprint report (BlancoMelo et al. 2020). ALI followed by the excessive activation of complement cascade was observed with MERS$\mathrm{CoV}$-murine model. In addition, alleviated lung damage was observed through the C5a-C5aR axis (Jiang et al. 2018). The role of the complement components (C3a and C5a) was obvious in lung inflammations of MERS (Jiang et al. 2019). Anaphylatoxin C5a is highly suggested as an inflammatory molecule, which can provoke pro-inflammatory cytokines (Guo and Ward 2005). As a result, the elevated levels of anaphylatoxins was considered as a clinical marker of ARDS (Hammerschmidt et al. 1980). Carvelli et al. (2020) revealed the direct correlation between the severity of SARS-CoV-2 and the level of soluble C5a. The C5a-C5aR1 (CD88) axis influences the regulation of inflammatory responses through the activation of neutrophils and monocytes in conditions like ALI and ARDS. The use of anti-C5aR1 therapeutic monoclonal antibodies prevented the recruitment and activation of human myeloid cells, and reduced ALI in human C5aR1 knock-in mice (Carvelli et al. 2020). In this review, we highlight the involvement of the complement system in aggravating the SARS-CoV-2 infection and suggest the therapeutic strategies through inhibiting the complement components.

\section{Complement cascade and SARS-CoV-2}

Though complement is a stakeholder of a healthy immune system, uncontrolled activation of complement leads to inflammation (Conigliaro et al. 2019). It was revealed that the viruses interact with complement components and its receptors to escape from the host-defense mechanisms (Lindahl et al. 2000). It is noteworthy that the unsolicited complement activation during coronavirus infection contributes to the SARS. The pathophysiology is driven by immune cells, which were observed in severe cases of SARS-CoV infection (Huang et al. 2020). Patients with SARS-CoV-2 are highly susceptible to develop ARDS. The impairment of respiratory function has been accredited with inflammation and infiltration of immune cells (Risitano et al. 2020). The overlapping features of ARDS such as diffuse alveolar damage (DAD) with edema, hyaline membrane formation, and inflammation were observed in COVID-19 patients (Magro et al. 2020). In a case study, immuno-histochemistry revealed the complement-mediated microvascular injury in five SARS-CoV-2 individuals. Extensive deposits of complement components C5b-9, C4d, and MASP2 were found in the lungs of two individuals infected with SARS-CoV-2. Further, thrombotic microvascular injury with the signs of viral cytopathic or fibroproliferative changes was observed by Magro et al. (2020).

The correlation among ARDS, complement cascade, and SARS-CoV pathogenesis was studied in complement deficient $\left(\mathrm{C}^{-/-}\right)$mouse model. Even though the viral load was unchanged, the pathogenesis of respiratory infections was reportedly decreased in $\mathrm{C} 3^{-/-}$mice. The deposition of complement molecules in the lungs of SARS-CoV-infected mice culminated in immune-mediated damages in the lungs (Gralinski et al. 2018). Jiang et al. (2018) reported the influence of complement molecules on lung damage in MERSCoV human DPP4 transgenic (hDPP4-Tg) mouse model. They further revealed excessive complement activation during viral infection, which altogether promotes acute lung injury and increases C5a and C5b-9 levels in sera and lung tissues, respectively. In contrast, the reduced inflammatory response was witnessed by inhibiting $\mathrm{C} 5 \mathrm{a}$ and its receptor. It was substantiated that the deregulated host immune response paves the way for the excessive complement activation, and promotes tissue damage through the C5a-C5aR axis. The autopsy provided evidence of severe interstitial pneumonia with excessive infiltration of lymphocytes, macrophages, and neutrophils in diffused and thickened alveolar septa (Jiang et al. 2018). The immune surveillance by complement molecules swiftly responds to viral infections and triggers

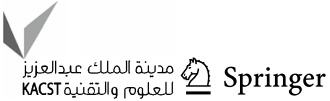


inflammation. For instance, elevated levels of downstream components of $\mathrm{C} 3$ were observed in patients affected with dengue fever, dengue hemorrhagic fever (DHF), and dengue shock syndrome (Nascimento et al. 2009). C3 is a vital pro-inflammatory peptide that facilitates robust pro-inflammatory and immune-modulatory signals in various viral infections (Prodeus et al. 1997). As a consequence, reduced peritoneal mast cell degranulation, TNF- $\alpha$, and neutrophil infiltration were observed with $\mathrm{C}^{-/-}$mice. Interestingly, treatment with purified $\mathrm{C} 3$ protein enhances the activation of mast cells, TNF- $\alpha$, and neutrophil infiltration (Prodeus et al. 1997). Very recently, the pivotal role of IgG on complement driven lung inflammation and pulmonary arterial hypertension (PAH) has been augmented (Frid et al. 2020).

\section{Complement components and inflammation}

Both complement molecules and neutrophils are key sentinels of innate immunity, and mediators of acute inflammation together lead to the modulation of thrombogenic pathways. During this process, a cross-talk is mediated by neutrophils between C5a receptor and tissue factors (Ritis et al. 2006). Neutrophilia in SARS-CoV infected patients is associated with poor outcome and extension of complement activation (Yen et al. 2006; Gralinski et al. 2018). Neutrophils driven by complement cascade are the first effector cells, which rapidly infiltrate into the site of infection. In response to potent chemotactic factor $\mathrm{C} 5 \mathrm{a}$ from complement activation, neutrophils migrate to remote tissues with their C5a receptors. C5 plays a dual role, in that, it attracts neutrophils through chemotaxis, and stimulates expression of tissue factor. Stimulation of neutrophils, monocytes, and other cells by $\mathrm{C} 5 \mathrm{a}$ headed towards the extrinsic coagulation pathway and promote thrombosis in remote sites (Ritis et al. 2006).

The anaphylatoxin C5a is a potent mediator of acute lung injury in MERS and SARS infection (Wang et al. 2015). Complement factor C5a is the strongest inflammatory peptide that triggers pro-inflammatory cytokines (Guo and Ward 2005). Increased levels of C5a in circulation was believed as a clinical marker of ARDS associated with severe sepsis, cytokine storm, and multiorgan failure (MOF) (Hammerschmidt et al. 1980). Upregulation of C3 and C5, and exuberant synthesis of pro-inflammatory cytokines was found in SARS-CoV-2 infection (Conti et al. 2020; Risitano et al. 2020). Consequently, the inflammatory milieu of lungs was accomplished by the release of anaphylatoxins C3a and C5a (Lindahl et al. 2000; Conti et al. 2020). The deposits of complement macromolecules C5b-9, C4d, and MASP 2 on the microvasculature of different organs have been reported (Magro et al. 2020). It was found that treatment with eculizumab (an anti-C5 monoclonal antibody) leads to hyperactivation of the complement system in $64 \%$ of hospitalized COVID-19 patients through which, it improved the health status (de Latour et al. 2020).

Anaphylatoxin C5a with its receptor (C5aR1) influences the activation of inflammatory responses by mobilizing neutrophil and monocytes. The role of $\mathrm{C} 5 \mathrm{a}-\mathrm{C} 5 \mathrm{aR} 1$ axis on SARS-CoV-2 pathogenesis is documented by Carvelli et al. (2020). Enhanced local complement activity is observed in COVID-19 patients' blood samples through transcriptomics analysis. In addition, the presence of $\mathrm{C} 5 \mathrm{~b} 9$ is witnessed in immuno-stained lung sections. Elevated expression of C5aR1 receptors on circulating neutrophils and monocytes were also observed in COVID-19 patients. Further, C5a is encountered in broncho-alveolar lavage fluid (BALF) of ARDS patients with COVID-19. The increased level of C5a in COVID-19 is perhaps contributed by the activation of lectin and classical complement pathway. Taken together, the blockade of C5a-C5aR1 is focused as a potential therapeutic approach. It was further evidenced by avdoralimab, a human monoclonal antibody and an antagonist of C5aR1 that prevents the binding of C5a (Carvelli et al. 2020).

ARDS is caused by fluid accumulation in the lungs. C5a, besides being an activator of neutrophils via C5a-receptor, is also a potent chemoattractant of neutrophils (Kew 2014). Recent reports suggest endothelial dysfunction results in the production of leukocyte adhesion molecules in COVID-19 patients (Teuwen et al. 2020). Leukocyte adhesion molecules along with cytokine storm and increased C5a levels may eventually increase the vascular permeability (Teuwen et al. 2020). Increased vascular permeability, in turn, allows the fluid to pass through the inter-endothelial gaps, and facilitates fluid accumulation in the lungs (Teuwen et al. 2020). The BALF contains proteins, lipids and a variety of cells including endothelial and immune cells from the adjacent tissues (Zhou et al. 2020). This mechanism also results in the adhesion and extravasation of monocytes and neutrophils into the tissue and alveoli, together with results in tissue damage. Targeting C5a is, therefore, one of the possible strategies to reduce the effects of hyper-immune activation in COVID-19.

\section{Complement inhibitors as potential therapeutic agents}

The merit of targeting complement components has gained attention in unusual clinical disorders such as paroxysmal nocturnal hemoglobinuria, and atypical hemolytic uraemic syndrome. The necessity of finding a new generation of complement inhibitors has been supported by clinical, preclinical, and human genome-wide analyses (Mastellos et al. 2019). Targeting complement molecules has been reported in vivo (Kumar et al. 2020) and with coronavirus-infected 
patients (Plosker 2012; Diurno et al. 2020). Presently, molecules impede the function of $\mathrm{C} 3, \mathrm{C} 5$, and convertases are considered as potential targets of COVID-19 (Diurno et al. 2020; Mastaglio et al. 2020). The complement molecules $\mathrm{C} 3$, and $\mathrm{C} 5$, convertases of $\mathrm{C} 3$ and $\mathrm{C} 5$, anaphylatoxins such as C3a, and C5a are considered as potential downstream components in the complement cascade (Mastellos et al. 2019). The above-said complement components are chiefly involved in the pathological conditions of a variety of inflammatory disorders, therefore, most inhibitors are designed to target these molecules. The complement inhibitors designed based on monoclonal antibody, protein, peptide, oligonucleotide, small molecule, and plant metabolite are represented in Table 2. Hitherto, eculizumab, an inhibitor

Table 2 Represents the list of complement inhibitors and their targets

\begin{tabular}{|c|c|c|c|c|c|}
\hline S. no. & Molecule & Target & Company & Stage & Clinical trial code/references \\
\hline \multicolumn{6}{|c|}{ Monoclonal antibody-based inhibitors } \\
\hline 1 & Eculizumab & $\mathrm{C} 5$ & Alexion & IV & NCT02574403 \\
\hline 2 & Ravulizumab & $\mathrm{C} 5$ & Alexion & III & $\begin{array}{l}\text { NCT03131219 } \\
\text { NCT02949128 }\end{array}$ \\
\hline 3 & Narsoplimab/OMS721 & MASP-2 & Omeros & II & $\begin{array}{l}\text { NCT02682407 } \\
\text { NCT03205995 }\end{array}$ \\
\hline 4 & AMY101 & $\mathrm{C} 3$ & Amyndas & I & NCT03316521 \\
\hline 5 & BDB-001 & $\mathrm{C} 5 \mathrm{a}$ & Staidson Biopharmaceuticals & II & NCT04449588 \\
\hline 6 & Sutimlimab & $\mathrm{C} 1 \mathrm{~s}$ & Sanofi/Bioverativ & III & NCT03347422, NCT03347396 \\
\hline 7 & Lampalizumab & Factor D & Genentech/Roche & III & NCT02247531, NCT02247479 \\
\hline 8 & Advoralimab/IPH5401 & C5aR1 & Innate Pharma & I & NCT03665129 \\
\hline 9 & Tesidolumab/LFG-316 & $\mathrm{C} 5$ & Novartis & I & NCT02878616 \\
\hline 10 & Pozelimab/REGN3918 & $\mathrm{C} 5$ & Regeneron & I & NCT03115996 \\
\hline 11 & SKY59/RO7112689 & $\mathrm{C} 5$ & Hoffmann-La Roche & $\mathrm{I} / \mathrm{II}$ & NCT03157635 \\
\hline 12 & АВР959 & $\mathrm{C} 5$ & Amgen & III & NCT03818607 \\
\hline 13 & SB12 & $\mathrm{C} 5$ & Samsung Bioepis & I & NCT03722329 \\
\hline \multicolumn{6}{|c|}{ Peptide/protein-based inhibitors } \\
\hline 14 & Conestat alfa & C1esterase & Pharming Group & II & NCT04414631 \\
\hline 15 & CINRYZE & $\mathrm{C} 1$ esterase & Shire Pharmaceuticals Ltd & Approved & NCT02052141 \\
\hline 16 & APL-2 & $\mathrm{C} 3$ & Apellis & II & NCT03453619 \\
\hline 17 & APL-9 & $\mathrm{C} 3$ & Apellis & II & NCT04402060 \\
\hline 18 & Coversin/rVA576 & $\mathrm{C} 5$ & Akari Therapeutics & III & NCT03829449 \\
\hline 19 & Zilucoplan & $\mathrm{C} 5$ & Ra Pharma & III & NCT04115293 \\
\hline 20 & IFX-1 & $\mathrm{C} 5 \mathrm{a}$ & InflaRx & II & NCT03712345 \\
\hline 21 & PMX-53 & $\mathrm{C} 5 \mathrm{a} / \mathrm{C} 5 \mathrm{aR}$ & & & Kumar et al. (2020) \\
\hline 22 & C1-INH/Berinert & $\mathrm{C} 1 \mathrm{r} / \mathrm{C} 1 \mathrm{~s}$ & Cedars-Sinai Medical Center & I & NCT02134314 \\
\hline 23 & Mirococept & $\mathrm{C} 3$ and $\mathrm{C} 5$ convertases & & & Xiao et al. (2016) \\
\hline 24 & TP10/ CDX1135 & C3/C5 convertases & Avant Immunotherapeutics & II & NCT00082121 \\
\hline \multicolumn{6}{|c|}{ Oligonucleotide-based inhibitors } \\
\hline 25 & Cemdisiran or ALN-CC5 & $\mathrm{C} 5$ & Alnylam Pharmaceuticals & II & NCT03841448 \\
\hline \multicolumn{6}{|c|}{ Small molecule-based inhibitors } \\
\hline 26 & CCX168 & C5aR1 & ChemoCentryx & II & NCT02384317 \\
\hline 27 & ACH0144471 & Factor D & Achillion & II & $\begin{array}{l}\text { NCT03459443 } \\
\text { NCT03124368 }\end{array}$ \\
\hline 28 & ACH145951 & Factor D & & & Yu et al. (2020) \\
\hline 29 & LPN023 & Factor B & Novartis & II & NCT03373461 \\
\hline 30 & $\begin{array}{l}\text { 1-(3,4-Dimethoxyphenyl)- } \\
\text { 3-(1-phenylethyl) urea }\end{array}$ & C5-convertase & & & Zhang et al. (2012) \\
\hline \multicolumn{6}{|c|}{ Plant metabolite-based inhibitors } \\
\hline 31 & Rosmarinic acid & C3 convertase & & & Englberger et al. (1988) \\
\hline 32 & Boswellic acid & C3 convertase & & & $\begin{array}{l}\text { Kapil and Moza (1992) and } \\
\text { Knaus and Wagner (1996) }\end{array}$ \\
\hline
\end{tabular}


of the complement system is the only FDA-approved drug (Soliris; Alexion Pharmaceuticals Inc., Cheshire, CT, USA). It is a humanized monoclonal antibody, which possesses a terminal complement inhibitor that binds to human C5 complement protein with high affinity, and blocks the generation of complement pro-inflammatory molecules C5a and C5b-9 (Rother et al. 2007). Eculizumab is used to treat various autoimmune diseases. Besides, patients with a confirmed diagnosis of SARS-CoV-2 infection, severe pneumonia, and ARDS were treated with eculizumab and showed better recovery. Anti-complement C5 therapy with eculizumab is a potent strategy to treat SARS-CoV-2 infection (Diurno et al. 2020). The schematic representation complement cascade with a special focus on the role of complement inhibitors during SARS-CoV-2 infection is depicted in Fig. 1.

Ravulizumab has been studied in patients with paroxysmal nocturnal hemoglobinuria (PNH), which was funded by
Alexion Pharmaceuticals. A rapid and sustained reduction in the complement-mediated hemolysis was observed while the patients were treated with ravulizumab (Kulasekararaj et al. 2019b). Six COVID-19 patients diagnosed with ARDS have been medicated with narsoplimab, a human immunoglobulin gamma 4 (IgG4)-based monoclonal antibody, which targets MASP2 in the MBL pathway. Narsoplimab is considered an effective medication for COVID-19 treatment, because it reduces endothelial cell damage, inflammation, and thrombotic risk (Rambaldi et al. 2020). Compstatin-based complement C3 inhibitor AMY-101 is administered for a patient infected with SARS-CoV-2 with the symptoms of ARDS. Intercepting C3 molecules block all downstream pro-inflammatory mediators of ARDS associated with SARS-CoV-2. The role of AMY-101 is well-studied as an anti-inflammatory agent under COVID-19 infection (Mastaglio et al. 2020). A very recent study reported an open label-2 cohort

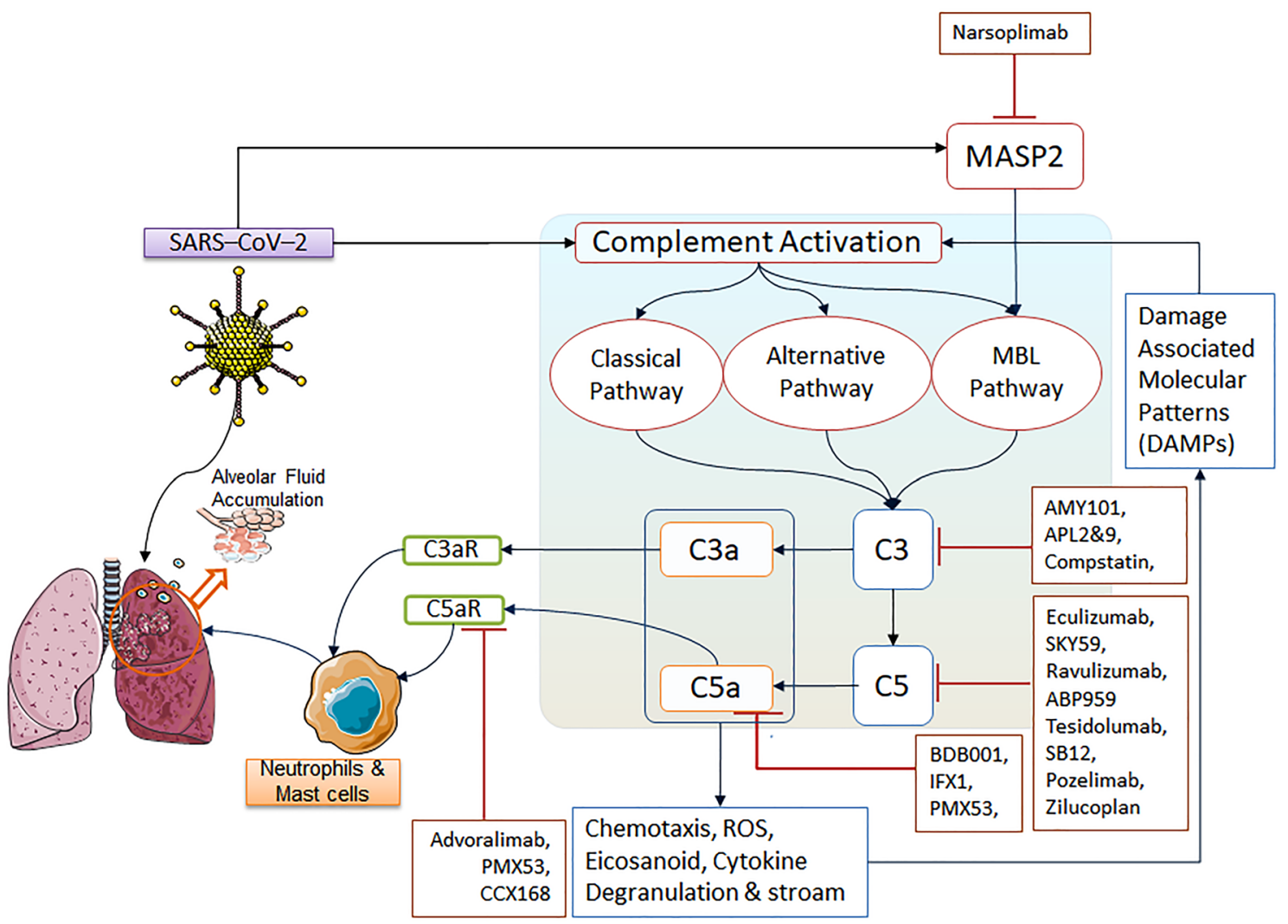

Fig. 1 Overview of the role of complement inhibitors targeting complement cascade during SARS-CoV-2 infection. Upon infection, SARS-CoV-2 primarily affects the respiratory tract and alveolar cells of the lung through ACE receptors. Subsequently, SARSCoV-2 directly interacts with MASP2 through a single N-linked glycosylation site in SARS-S and activates the MBL pathway. The classical and alternative pathways are also activated as a part of the viral defense, and triggers complement component $\mathrm{C} 3$, which culminates in increased secretion of $\mathrm{C} 3 \mathrm{a}$ and $\mathrm{C} 5 \mathrm{a}$. These anaphylatoxins trigger cytokines storm, mast cells degranulation, activation of leukocytes and its infiltration into alveoli. The unsolicited activation of complement cascade starts here through DAMPs, and makes the lung vulnerable to complement deposits, excess neutrophil infiltration and pathogenesis of ARDS. Hence, inhibiting the downstream complement components such as $\mathrm{C} 3$ and $\mathrm{C} 5$, the convertases of $\mathrm{C} 3$ and $\mathrm{C} 5$, the anaphylatoxins $\mathrm{C} 3 \mathrm{a}$ and $\mathrm{C} 5 \mathrm{a}$ and its receptors will be a better approach to reduce the pathogenesis of ARDS. Inhibition of the above complement components would reduce the severity of the pathological conditions caused by the virus. Moreover, it will provide a window period for eliminating viral load with antiviral drugs for COVID-19 patients 
trial of recombinant C5a monoclonal antibody BDB-001 in COVID-19 patients and showed improved clinical conditions within a few days of treatment (Gao et al. 2020).

The potential role of Sutimlimab on C1s inhibition was revealed from phase 3 cardinal study with Cold Agglutinin Disease (CAD) patients (Röth et al. 2019). FDA has granted a review of Sutimlimab for the treatment of hemolysis in adult patients with CAD. Since patients with COVID-19 are also displaying the symptoms of autoimmune hemolytic anemia (AIHA) (Lazarian et al. 2020), Sutimlimab can be used as a choice for the treatment of coronavirus. Similarly, the clinical use of lampalizumab and its pharmacokinetic, pharmacodynamic, and biodistribution studies on the inhibition of complement component factor $\mathrm{D}$ has been reported with Cynomolgus Monkey (Le et al. 2015). Further, the direct activation of alternative pathways by SARSCoV-2 spike protein has been reported by Yu et al. (2020). They have used ACH145951, an antagonist of factor D to eliminate the expression of alternative pathways by inhibiting factor $\mathrm{D}$, thus resulting in the prevention of $\mathrm{C} 3 \mathrm{c}$ and C5b-9 accumulation. Though factor D targeting is proved as a potential approach to diminish undesirable complement expression, lampalizumab can also experimented for COVID-19. Targeting complement component C5 is considered as the positive approach for treating pathological conditions of COVID-19 (Diurno et al. 2020). It can be aided using monoclonal antibodies such as Pozelimab (Latuszek et al. 2020), Tesidolumab (Jordan et al. 2020), Crovalimab/ SKY59 (Röth et al. 2020), and ABP 959 (Chow et al. 2020), which are under various phase trials. Given the potential of these antibodies in inhibiting C5, we suggest it for COVID19 treatment.

Conestat Alfa (Ruconest) is a human recombinant $\mathrm{C} 1$ esterase inhibitor obtained from genetically modified rabbits' milk. The drug was approved in the United States for the treatment of acute attacks and hereditary angioedema (Cruz 2015). University Hospital, Basel, Switzerland sponsored the phase 2 clinical trial of Conestat Alfa for noncritical SARS-CoV-2 pneumonia patients against the disease progression of ALI and ARDS. Cinryze, another successful inhibitor of $\mathrm{C} 1$ esterase has been used in hereditary angioedema (HAE) (Gupta et al. 2018). Cinryze can also be explored for treating pathological conditions of ALI and ARDS since it is similar to Conestat Alfa, which also targets $\mathrm{C} 1$ esterase. Autoimmune hemolytic anemia (AIHA) is a rare complement-dependent autoimmune disease. Systemic inhibition of $\mathrm{C} 3$ complement components with APL-2 has been demonstrated in phase- 2 open-label study against AIHA (Grossi et al. 2018). APL-2 is in phase 3 trial for the patients with $\mathrm{PNH}$, a complement-mediated disease. Based on these auxiliary reports, we suggest using Conestat Alfa for the treatment of pathological conditions of coronavirus. Coversin (Kuhn et al. 2016) and Zilucoplan (Howard Jr et al.
2020) are C5-specific complement inhibitors reported for their activity against anti-hemolytic and Severe Generalized Myasthenia Gravis (SGMS). Complement-mediatedhemolysis is also observed with SARS-CoV-2 patients by $\mathrm{Yu}$ et al. (2020). Hence, Coversin and Zilucoplan, antagonists of C5 can be exploited for treating COVID-19 pathological conditions. Anaphylatoxins C3a and C5a mobilize the inflammatory mediators to alveoli of the lungs. The molecules IFX-1 and PMX-53 have been reported as antagonists of C5a ( $\mathrm{Li}$ et al. 2014; Lu et al. 2020) opt for the pathological conditions of ARDS. Mirococept (APT070) (Xiao et al. 2016) and TP10 (Li et al. 2006) are proved to inhibit the convertase family of enzymes in various animal studies. Inhibitors of $\mathrm{C} 3$ and $\mathrm{C} 5$ convertases have the ability to block downstream complement components involved in the pathogenesis of ARDS, and using these inhibitors to treat COVID-19 patients would be appropriate.

Avacopan (CCX168), Danicopan (ACH-0144471), LNP023, and 1-(3,4-dimethoxyphenyl)-3-(1-phenylethyl) urea are small molecules accounted for their inhibitor activity against complement components. Avacopan is proved as C5aR antagonist by phase 2 CLEAR trial in patients with anca associated vasculitis (AAV) (Bunch et al. 2018). Drugs targeting C5aR are under clinical trial for COVID-19 patients with severe pneumonia; thus, Avacopan also opts for the studies of SARS-CoV-2. Factor D is a serine protease allowing the formation of a $\mathrm{C} 3$ convertase in the complement pathway. Danicopan is proved as an inhibitor of factor D with Paroxysmal Nocturnal Hemoglobinuria (PNH) patients in phase 2 open-label study (Kulasekararaj et al. 2019a). LNP023 is an orally-administered inhibitor of factor $\mathrm{B}$, which binds to its active site of factor $\mathrm{B}$ and results in blockade of C3 cleavage (Zipfel et al. 2019). Factors B and $\mathrm{D}$ are essential components of alternative pathways that can proteolytically activate $\mathrm{C} 3$ and $\mathrm{C} 5$ convertases. Though factor D targeting drugs are already under clinical trials of COVID-19, Danicopan and LNP023 can be explored against pathological conditions of SARS-CoV-2. A small-molecule based on 1-(3,4-dimethoxyphenyl)-3-(1-phenylethyl) urea with the effect of inhibiting C5-convertase was reported by Zhang et al. (2012). The small molecule inhibitors focus on the C5 component as a potential target, and its mechanism of action on C5 inhibition was demonstrated by Jendza et al. (2019).

Phytochemicals exhibit immunomodulatory effects and are considered as alternative medicine. Usage of phytochemicals to hamper the breakdown of $\mathrm{C} 3$ and $\mathrm{C} 5$ might be a promising strategy to prevent or reduce lung inflammation in COVID-19 patients. Interestingly, rosmarinic acid and boswellic acid extracted from Rosmarinus officinalis and Boswellia serrata, respectively, have been reported to inhibit complement $\mathrm{C} 3$ convertase. The effect of rosmarinic acid on $\mathrm{C} 3$ convertase was demonstrated with rat and guinea 
pig models of acute lung injury and shock. It was found that rosmarinic acid was involved in the inhibition of C3 convertase, complement activation, and complement-dependent inflammation (Englberger et al. 1988). In addition, the role of boswellic acid on the inhibition of C3-convertase was demonstrated in vitro and in vivo (Kapil and Moza 1992; Knaus and Wagner 1996).

\section{Conclusion}

Even though the complement system acts as a crucial player of the innate and adaptive immune system, its dysfunction escalates the inflammation in ALI, ARDS, etc. The anaphylatoxins such as $\mathrm{C} 3 \mathrm{a}$ and C5a play a central role in mobilizing the inflammatory mediators to the alveoli. The deposit of complement components on alveoli of lungs has been witnessed by animal studies and autopsy results. The complement deficient-mice model authenticated the role of complement inhibitors under severe pathological conditions of MERS. Therefore, inhibition of complement components would perhaps be an appropriate strategy in downing the pathology of COVID-19. It is interesting to note that various inhibitors are available and show great promise against MERS, SARS, and ARDS. The complement inhibitors usually target various components of the cascade and address various effector pathways and its downstream effects. Therefore, a detailed understanding of complement inhibitors, their molecular target, mode of action, regulatory loops and networks, crosstalk with other immunological molecules, acute and chronic side-effects will grant the use of these inhibitors for the benefit of COVID-19 patients. Conclusively, an emerging list of novel complement inhibitors and the concurrent results in clinical trials show that complement inhibitors are very promising drugs for any inflammatory diseases.

Acknowledgements The authors grateful to Dr. Devraj Sankarganesh, Postdoctoral Researcher, Department of Microbial Biotechnology, Bharathiar University, Coimbatore, India, for critically read the manuscript and provided comments.

\section{Compliance with ethical standards}

Conflict of interest The authors don't have any conflict of interest.

\section{References}

Ábel G, Agnello V (2004) Complement deficiency and systemic lupus erythematosus. In: Lahita RG (ed) Systemic lupus erythematosus, vol 4. Academic Press, San Diego, pp 173-201

Agrawal P, Nawadkar R, Ojha H et al (2017) Complement evasion strategies of viruses: an overview. Front Microbiol 8:1117
Beutler B (2004) Innate immunity: an overview. Mol Immunol 40:845-859

Blanco-Melo D, Nilsson-Payant B, Liu W-C et al (2020) SARS$\mathrm{CoV}-2$ launches a unique 15 transcriptional signature from in vitro, ex vivo, and invivo systems. BioRxiv (Pre-print)

Bunch DO, Deng J, McInnis EA et al (2018) OP0046 Effect of a selective c5ar antagonist, avacopan (CCX168), on plasma complement levels in anca associated vasculitis (AAV). Ann Rheum Dis 77:74-75. https://doi.org/10.1136/annrheumdis-2018-eular .6032

Cameron MJ, Kelvin AA, Leon AJ et al (2012) Lack of innate interferon responses during SARS coronavirus infection in a vaccination and reinfection ferret model. PLoS ONE 7:e45842

Carroll MC (2004) The complement system in regulation of adaptive imunity. Nat Immunol 5:981-986

Carvelli J, Demaria O, Vély F, Batista L, Benmansour NC, Fares J, Carpentier S, Thibult ML, Morel A, Remark R, André P (2020) Association ofCOVID-19 inflammation with activation of the C5a-C5aR1 axis. Nature. https://doi.org/10.1038/s4158 6-020-2600-6

Chow DA (2005) Physiological activities of the natural immune system. In: Bertók L, Chow D (eds) Natural immunity. Elsevier, Amsterdam, pp 311-329

Chow V, Pan J, Chien D et al (2020) A randomized, double-blind, single-dose, three-arm, parallel group study to determine pharmacokinetic similarity of ABP 959 and eculizumab (Soliris ${ }^{\circledR}$ ) in healthy male subjects. Eur J Haematol 105:66-74. https://doi. org/10.1111/ejh.13411

Conigliaro P, Triggianese P, Ballanti E et al (2019) Complement, infection, and autoimmunity. Curr Opin Rheumatol 31:532-541

Conti P, Ronconi G, Caraffa AL et al (2020) Induction of pro-inflammatory cytokines (IL-1 and IL-6) and lung inflammation by Coronavirus-19 (COVI-19 or SARS-CoV-2): anti-inflammatory strategies. J Biol Regul Homeost Agents 34:1

Cree BAC (2014) Chapter 10-Genetics of primary progressive multiple sclerosis. In: Goodin CN (ed) Multiple sclerosis and related disorders. Elsevier, Amsterdam, pp 211-230

Cruz MP (2015) Conestat alfa (ruconest): first recombinant c1 esterase inhibitor for the treatment of acute attacks in patients with hereditary angioedema. Pharm Ther 40:109-114

de Latour RP, Bergeron A, Lengline E, Dupont T, Marchal A, Galicier L, de Castro N, Bondeelle L, Darmon M, Dupin C, Dumas G, Leguen P, Madelaine I, Chevret S, Molina JM, Azoulay E, Bacchi VF, CORE GROUP (2020) Complement C5 inhibition in patients with COVID-19 - a promising target?. Haematologica. https://doi. org/10.3324/haematol.2020.260117

Diurno F, Numis FG, Porta G et al (2020) Eculizumab treatment in patients with COVID-19: preliminary results from real life ASL Napoli 2 Nord experience. Eur Rev Med Pharmacol Sci 24:4040-4047

Dobó J, Harmat V, Beinrohr L et al (2009) MASP-1, a promiscuous complement protease: structure of its catalytic region reveals the basis of its broad specificity. J Immunol 183:1207-1214. https:// doi.org/10.4049/jimmunol.0901141

Du Clos TW, Mold C (2013) Complement in host deficiencies and diseases. In: Rich RR, Fleisher TA, Shearer WT et al (eds) Content repository only! Elsevier, London, pp 252-269

Englberger W, Hadding U, Etschenberg E et al (1988) Rosmarinic acid: a new inhibitor of complement C3-convertase with anti-inflammatory activity. Int J Immunopharmacol 10:729-737

Farrar CA, Zhou W, Lin T, Sacks SH (2006) Local extravascular pool of $\mathrm{C} 3$ is a determinant of postischemic acute renal failure. FASEB J 20:217-226

Ferreira VP, Pangburn MK, Cortés C (2010) Complement control protein factor $\mathrm{H}$ : the good, the bad, and the inadequate. Mol Immunol 47:2187-2197 
Forneris F, Gros P (2013) Complement factor D. In: Rawlings ND, Salvesen PE (eds) Handbook of proteolytic enzymes. Academic Press, New York, pp 2841-2848

Frid MG, McKeon BA, Thurman JM et al (2020) Immunoglobulin-driven complement activation regulates proinflammatory remodeling in pulmonary hypertension. Am J Respir Crit Care Med 201:224-239

Gao T, Hu M, Zhang X et al (2020) Highly pathogenic coronavirus $\mathrm{N}$ protein aggravates lung injury by MASP-2-mediated complement over-activation. medRxiv. https://doi. org/10.1101/2020.03.29.20041962

Gralinski LE, Sheahan TP, Morrison TE et al (2018) Complement activation contributes to severe acute respiratory syndrome coronavirus pathogenesis. MBio 9:e01753-e1818

Grossi F, Shum MK, Gertz MA et al (2018) Inhibition of C3 with APL-2 results in normalisation of markers of intravascular and extravascular hemolysis in patients with autoimmune hemolytic anemia (AIHA). Blood 132:3623. https://doi.org/10.1182/blood -2018-99-119468

Guo R-F, Ward PA (2005) Role of C5a in inflammatory responses. Annu Rev Immunol 23:821-852

Gupta R, Balduzzi J, Davis-Lorton M (2018) C1-esterase inhibitor $\left(\right.$ Cinryze $\left.^{\circledR}\right)$ use in the treatment of pediatric hereditary angioedema. Immunotherapy 10:635-642. https://doi.org/10.2217/ imt-2017-0049

Hammerschmidt D, Hudson L, Weaver LJ et al (1980) Association of complement activation and elevated plasma-C5a with adult respiratory distress syndrome: pathophysiological relevance and possible prognostic value. Lancet 315:947-949

Howard JF Jr, Nowak RJ, Wolfe GI et al (2020) Clinical effects of the self-administered subcutaneous complement inhibitor zilucoplan in patients with moderate to severe generalized myasthenia gravis: results of a phase 2 randomized, double-blind, placebocontrolled, multicenter clinical trial. JAMA Neurol 77:582-592. https://doi.org/10.1001/jamaneurol.2019.5125

Huang C, Wang Y, Li X et al (2020) Clinical features of patients infected with 2019 novel coronavirus in Wuhan, China. Lancet, China. https://doi.org/10.1016/S0140-6736(20)30183-5

Jendza K, Kato M, Salcius M et al (2019) A small-molecule inhibitor of C5 complement protein. Nat Chem Biol 15:666-668

Jiang Y, Zhao G, Song N et al (2018) Blockade of the C5a-C5aR axis alleviates lung damage in hDPP4-transgenic mice infected with MERS-CoV. Emerg Microbes Infect 7:1-12

Jiang Y, Li J, Teng Y et al (2019) Complement receptor C5aR1 inhibition reduces pyroptosis in hDPP4-transgenic mice infected with MERS-CoV. Viruses 11:39

Jordan SC, Kucher K, Bagger M et al (2020) Intravenous immunoglobulin significantly reduces exposure of concomitantly administered anti-C5 monoclonal antibody tesidolumab. Am J Transplant 20:2581-2588. https://doi.org/10.1111/ajt.15922

Kapil A, Moza N (1992) Anticomplementary activity of boswellic acids-an inhibitor of C3-convertase of the classical complement pathway. Int J Immunopharmacol 14:1139-1143

Kew RR (2014) The complement system. In: McManus LM, Mitchell RN (eds) Academic Press, San Diego, pp 231-243

Kjaer TR, Thiel S, Andersen GR (2013) Toward a structure-based comprehension of the lectin pathway of complement. Mol Immunol 56:222-231

Knaus U, Wagner H (1996) Effects of boswellic acid of Boswellia serrata and other triterpenic acids on the complement system. Phytomedicine 3:77-80

Krishnan V, Xu Y, Macon K et al (2009) The structure of C2b, a fragment of complement component $\mathrm{C} 2$ produced during $\mathrm{C} 3$ convertase formation. Acta Crystallogr Sect D Biol Crystallogr $65: 266-274$
Kuhn N, Schmidt CQ, Schlapschy M, Skerra A (2016) PASylated coversin, a C5-specific complement inhibitor with extended pharmacokinetics, shows enhanced anti-hemolytic activity in vitro. Bioconjug Chem 27:2359-2371. https://doi. org/10.1021/acs.bioconjchem.6b00369

Kulasekararaj A, Risitano AM, Maciejewski JP et al (2019) A phase 2 open-label study of danicopan (ACH-0144471) in patients with paroxysmal nocturnal hemoglobinuria (PNH) who have an inadequate response to eculizumab monotherapy. Blood 134:3514. https://doi.org/10.1182/blood-2019-124748

Kulasekararaj AG, Hill A, Rottinghaus ST et al (2019) Ravulizumab (ALXN1210) vs eculizumab in C5-inhibitor-experienced adult patients with PNH: the 302 study. Blood 133:540-549

Kumar V, Lee JD, Clark RJ et al (2020) Preclinical pharmacokinetics of complement C5a receptor antagonists PMX53 and PMX205 in mice. ACS Omega 5:2345-2354. https://doi.org/10.1021/ acsomega.9b03735

Latuszek A, Liu Y, Olsen O et al (2020) Inhibition of complement pathway activation with pozelimab, a fully human antibody to complement component C5. PLoS ONE 15:e0231892

Lazarian G, Quinquenel A, Bellal M et al (2020) Autoimmune haemolytic anaemia associated with COVID-19 infection. Br J Haematol 190:29-31. https://doi.org/10.1111/bjh.16794

Le KN, Gibiansky L, Good J et al (2015) A mechanistic pharmacokinetic/pharmacodynamic model of factor D inhibition in cynomolgus monkeys by lampalizumab for the treatment of geographic atrophy. J Pharmacol Exp Ther 355:288-296. https ://doi.org/10.1124/jpet.115.227223

Li JS, Jaggers J, Anderson PAW (2006) The use of TP10, soluble complement receptor 1, in cardiopulmonary bypass. Expert Rev Cardiovasc Ther 4:649-654. https://doi.org/10.1586/14779 072.4.5.649

Li G, Fan R-M, Chen J-L et al (2014) Neuroprotective effects of argatroban and C5a receptor antagonist (PMX53) following intracerebral haemorrhage. Clin Exp Immunol 175:285-295. https://doi.org/10.1111/cei.12220

Lindahl G, Sjöbring U, Johnsson E (2000) Human complement regulators: a major target for pathogenic microorganisms. Curr Opin Immunol 12:44-51

Ling MT, Tu W, Han Y et al (2012) Mannose-binding lectin contributes to deleterious inflammatory response in pandemic H1N1 and avian H9N2 infection. J Infect Dis 205:44-53

Lu JD, Milakovic M, Ortega-Loayza AG et al (2020) Pyoderma gangrenosum: proposed pathogenesis and current use of biologics with an emphasis on complement C5a inhibitor IFX-1. Expert Opin Investig Drugs. https://doi.org/10.1080/13543 784.2020.1819981

Magro C, Mulvey JJ, Berlin D, Nuovo G, Salvatore S, Harp J, BaxterStoltzfus A, Laurence J (2020) Complement associated microvascular injury and thrombosis in the pathogenesis of severe COVID-19 infection: A report of five cases. Transl Res 220:113. https://doi.org/10.1016/j.trs1.2020.04.007

Mak TW, Saunders ME (2006) 19-Complement. Academic Press, Burlington, pp 553-581

Mak TW, Saunders ME (eds) (2014) Chapter 3-Innate immunity, 2nd edn. Academic Cell, Boston, pp 55-83

Maloney BE, Perera KD, Saunders DRD, Shadipeni N, Fleming SD (2020) Interactions of viruses and the humoral innate immune response. Clin Immunol 212:108351. https://doi.org/10.1016/j. clim.2020.108351

Mastaglio S, Ruggeri A, Risitano AM, Angelillo P, Yancopoulou D, Mastellos DC, Huber-Lang M, Piemontese S, Assanelli A, Garlanda C, Lambris JD, Ciceri F (2020) The first case of COVID-19 treated with the complement C3 inhibitor AMY101. Clin Immunol 215:108450. https://doi.org/10.1016/j. clim.2020.108450

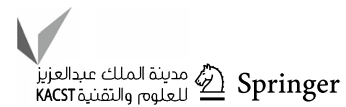


Mastellos DC, Ricklin D, Lambris JD (2019) Clinical promise of next-generation complement therapeutics. Nat Rev Drug Discov 18:707-729

Matsushita M, Fujita T (1992) Activation of the classical complement pathway by mannose-binding protein in association with a novel C1s-like serine protease. J Exp Med 176:1497-1502

Medzhitov R, Janeway C Jr (2000) Innate immunity. N Engl J Med 343:338-344

Mollnes TE, Song W-C, Lambris JD (2002) Complement in inflammatory tissue damage and disease. Trends Immunol 23:61-64

Nascimento EJM, Silva AM, Cordeiro MT, Brito CA, Gil LHVG, Braga-Neto U et al (2009) Alternative Complement Pathway Deregulation IsCorrelated with Dengue Severity. PLoS ONE 4(8):e6782. https://doi.org/10.1371/journal.pone.0006782

Pangburn MK (1986) 2-The alternative pathway. In: Ross GD (ed) Immunobiology of the complement system. Academic Press, New York, pp 45-62

Plosker GL (2012) Recombinant human C1 inhibitor (conestat alfa). BioDrugs 26:315-323

Prodeus AP, Zhou X, Maurer M et al (1997) Impaired mast celldependent natural immunity in complement $\mathrm{C} 3$-deficient mice. Nature 390:172-175. https://doi.org/10.1038/36586

Rambaldi A, Gritti G, Micò MC, Frigeni M, Borleri G, Salvi A, Landi F, Pavoni C, Sonzogni A, Gianatti A, Binda F, Stefano Fagiuoli S, Marco FD, Lorini L, Remuzzi G, Whitaker S, Demopulos G (2020) Endothelial injury and thrombotic microangiopathy in COVID-19: Treatment with the lectin-pathway inhibitor narsoplimab. Immunobiology. https://doi.org/10.1016/j.imbio.2020.15200 1

Ricklin D, Reis ES, Mastellos DC et al (2016) Complement component C3-the "Swiss Army Knife" of innate immunity and host defense. Immunol Rev 274:33-58

Risitano AM, Mastellos DC, Huber-Lang M, Yancopoulou D, Garlanda C, Ciceri F, Lambris JD (2020) Complement as a target in COVID-19? Nat Rev Immunol 20:343-344. https://doi. org/10.1038/s41577-020-0320-7

Ritis K, Doumas M, Mastellos D et al (2006) A novel C5a receptortissue factor cross-talk in neutrophils links innate immunity to coagulation pathways. J Immunol 177:4794-4802

Röth A, Barcellini W, D'Sa S et al (2019) Inhibition of complement $\mathrm{C} 1 \mathrm{~s}$ with sutimlimab in patients with cold agglutinin disease (CAD): results from the phase 3 cardinal study. Blood. https:// doi.org/10.1182/blood-2019-132490

Röth A, Nishimura J, Nagy Z et al (2020) The complement C5 inhibitor crovalimab in paroxysmal nocturnal hemoglobinuria. Blood 135:912-920. https://doi.org/10.1182/blood.2019003399

Rother RP, Rollins SA, Mojcik CF et al (2007) Discovery and development of the complement inhibitor eculizumab for the treatment of paroxysmal nocturnal hemoglobinuria. Nat Biotechnol 25:12561264. https://doi.org/10.1038/nbt1344

Rus H, Cudrici C, Niculescu F (2005) The role of the complement system in innate immunity. Immunol Res 33:103-112

Sarma VJ, Huber-Lang M, Ward PA (2006) Complement in lung disease. Autoimmunity 39:387-394. https://doi.org/10.1080/08916 930600739456

Schwaeble WJ, Lynch NJ, Clark JE, Marber M, Samani NJ, Mohammed Ali Y, Dudler T, Parent B, Lhotta K, Wallis R, Farrar CA, Sacks S, Lee H, Zhang M, Iwaki D, Takahashi M, Fujita T, Tedford CE, Stover CM (2011) Targeting of mannan-binding lectinassociated serine protease- 2 confers protection from myocardial and gastrointestinal ischemia/reperfusion injury. Proceedings of the National Academy of Sciences 108(18):7523-7528. https:// doi.org/10.1073/pnas.1101748108

Schwaeble WJ, Ali YM, Sim RB (2020) Chapter 14-The roles and contributions of the complement system in the pathophysiology of autoimmune diseases. In: Rose NR, Mackay IR (eds) The autoimmune system, 6th edn. Academic Press, Cambridge, pp 263-273

Shen B, Yi X, Sun Y et al (2020) Proteomic and metabolomic characterization of COVID-19 patient sera. Cell 182:59-72

Smith JG, Nemerow GR (2019) Complement seals a virus to block infection. Cell Host Microbe 25:482-483. https://doi. org/10.1016/j.chom.2019.03.010

Stoermer KA, Morrison TE (2011) Complement and viral pathogenesis. Virology 411:362-373

Sun S, Zhao G, Liu C et al (2013) Inhibition of complement activation alleviates acute lung injury induced by highly pathogenic avian influenza H5N1 virus infection. Am J Respir Cell Mol Biol 49:221-230

Teuwen L-A, Geldhof V, Pasut A, Carmeliet P (2020) COVID-19: the vasculature unleashed. Nat Rev Immunol 20:389-391. https://doi. org/10.1038/s41577-020-0343-0

Tu X, Chong WP, Zhai Y et al (2015) Functional polymorphisms of the CCL2 and MBL genes cumulatively increase susceptibility to severe acute respiratory syndrome coronavirus infection. J Infect 71:101-109

Wang Y, Liu L (2016) The membrane protein of severe acute respiratory syndrome coronavirus functions as a novel cytosolic pathogen-associated molecular pattern to promote beta interferon induction via a Toll-like-receptor-related TRAF3-independent mechanism. MBio 7:e01872-e1915. https://doi.org/10.1128/ mBio.01872-15

Wang R, Xiao H, Guo R et al (2015) The role of C5a in acute lung injury induced by highly pathogenic viral infections. Emerg Microbes Infect. https://doi.org/10.1038/emi.2015.28

Xiao F, Ma L, Zhao M et al (2016) APT070 (mirococept), a membrane-localizing $\mathrm{C} 3$ convertase inhibitor, attenuates early human islet allograft damage in vitro and in vivo in a humanized mouse model. Br J Pharmacol 173:575-587

Yang D (2013) Chapter 85-Anaphylatoxins. In: Kastin AJ (ed) Handbook of biologically active peptides. Academic Press, Boston, pp 625-630

Yen Y-T, Liao F, Hsiao C-H et al (2006) Modeling the early events of severe acute respiratory syndrome coronavirus infection in vitro. J Virol 80:2684-2693

Yu J, Yuan X, Chen H et al (2020) Direct activation of the alternative complement pathway by SARS-CoV-2 spike proteins is blocked by factor D inhibition. Blood. https://doi.org/10.1182/blood.20200 08248

Zhang H, Zhou G, Zhi L et al (2005) Association between mannosebinding lectin gene polymorphisms and susceptibility to severe acute respiratory syndrome coronavirus infection. J Infect Dis 192:1355-1361

Zhang M, Yang X-Y, Tang W et al (2012) Discovery and structural modification of 1-phenyl-3-(1-phenylethyl) urea derivatives as inhibitors of complement. ACS Med Chem Lett 3:317-321. https ://doi.org/10.1021/ml300005w

Zhou Y, Lu K, Pfefferle S et al (2010) A single asparagine-linked glycosylation site of the severe acute respiratory syndrome coronavirus spike glycoprotein facilitates inhibition by mannose-binding lectin through multiple mechanisms. J Virol 84:8753-8764

Zhou Z, Ren L, Zhang L, Zhong J, Xiao Y, Jia Z, Guo L, Yang J, Wang C, Jiang S, Yang D, Zhang G, Li H, Chen F, Xu Y, Chen M, Gao Dong J, Liu B, Zhang Z, Wang W, He K, Jin Q, Li M, Wang J (2020) Heightened innate immune responses in the respiratory tract of COVID-19 patients. Cell Host Microbe. https:// doi.org/10.1016/j.chom.2020.04.017

Zipfel PF, Wiech T, Rudnick R et al (2019) Complement inhibitors in clinical trials for glomerular diseases. Front Immunol 10:2166 